\title{
10-V Round-Robin Test Conducted on a Solid-State DC Voltage Standard
}

\author{
LATIKA S. R. BECKER, MEMBER, IEEE, BRUCE F. FIELD, MEMBER, IEEe, AND THOMAS E. KIESS
}

\begin{abstract}
A round-robin comparison of 10-V dc standards was conducted through the cooperative efforts of the U.S. Primary Standards Laboratory, U.S. Navy East and West Laboratories, U.S. Air Force Primary Standards Laboratory (APSL), and the National Bureau of Standards (NBS). A transfer uncertainty of $0.11 \mathrm{ppm}$ (95-percent confidence interval) was obtained using solid-state dc voltage references. This paper describes the round-robin test, presents the results obtained in the evaluation of the transfer uncertainty of $10-\mathrm{V}$ solid-state standards, and provides information on the relative quality of various test methods used in this round-robin.
\end{abstract}

\section{INTRODUCTION}

$\mathbf{S}^{\circ}$ OLID-STATE dc voltage references are more rugged and reliable than conventional electrochemical standard cells. These characteristics are very appealing when transferring voltage references from one laboratory to another over large distances.

Historically, standards laboratories have maintained their volt using a group of saturated standard cells. These are references for precision electrical measurements used for calibrating digital voltmeters or other devices. Many modern instruments require support at the $10-\mathrm{V}$ level and this has been done by stepping from the $1-\mathrm{V}$ level up to the 10-V level and accepting the resulting decrease in calibration accuracy. Transferring the volt at the $10-\mathrm{V}$ level, where the greatest accuracy is required to support new instrumentation, eliminates the need for scaling to $10 \mathrm{~V}$ at lower level laboratories. This enables Department of Defense (DoD) primary standards laboratories and similar industrial laboratories to perform the $1-10-\mathrm{V}$ step-up once with great care and then transfer the volt at $10 \mathrm{~V}$ to many lower echelon laboratories.

An experiment was devised to evaluate the uncertainty with which $10-\mathrm{V}$ solid-state standards could be used to determine the difference between the units of voltage in any two laboratories, and secondly to determine the differences among the units of voltage at $10 \mathrm{~V}$ in the DoD primary laboratories where the differences iñay partially be the result of systematic errors in scaling from the

Manuscript received March 25, 1986.

L. S. R. Becker was with the U.S. Army Test, Measurement, and Diagnostic Equipment Support Group, Redstone Arsenal, AL 35898. She is now with the U.S. Army Strategic Defense Command, DASD-H-F. Huntsville, AL 35807.

B. F. Field is with the National Bureau of Standards, Washington, DC 20234.

T. E. Kiess is with the Electricity Division, National Bureau of Standards, Gaithersburg, MD 20899.

IEEE Log Number 8610597.
1-V level of standard cells to $10 \mathrm{~V}$. Four DoD laboratories (Labs A-D) and NBS participated in a round-robin experiment involving three solid-state standards. The standards were calibrated at NBS at the beginning and end of the experiment and were shipped as a group to each of the other laboratories.

\section{Measurement Methods}

The first step in coordinating the $10-\mathrm{V}$ round-robin comparison was to review each participant's methodology used for the measurement of $10-\mathrm{V}$ standards. It was clear from the operating procedures of these laboratories that all have good capabilities in dc voltage measurements and each laboratory maintains direct traceability to NBS at the $1-\mathrm{V}$ level by transfer of standard cells. The five participating laboratories disseminate their $10-\mathrm{V}$ standard using the measurement systems described below:

Lab $A$

A group of ten series-connected saturated standard cells (having the value of approximately $10 \mathrm{~V}$ ) is used as the system reference. The voltage of the solid-state transport standard is determined by measuring the difference between the system reference and the transport standard by use of a digital voltmeter (DVM). The DVM is calibrated directly in terms of the value of a saturated standard cell before each measurement.

\section{$L a b B$}

A Kelvin-Varley voltage divider driven by an adjustable $11-\mathrm{V}$ solid-state source is standardized directly in terms of the value of a group of four series-connected saturated standard cells. Then the divider is set at $10 \mathrm{~V}$ and compared to the output of the transport standard by means of a null detector.

\section{Lab C}

A $10-\mathrm{V}$ solid-state standard is used to drive a KelvinVarley voltage divider, the output of which is compared to six saturated standard cells connected in series. Then the divider is set at $10 \mathrm{~V}$ and compared to the output of the transport standard. Differences are read directly from a null detector.

\section{Lab D}

The output of the transport standard is connected directly to the input of a Kelvin-Varley voltage divider. 
With the dials sct to $8.144 \times x \mathrm{~V}$, the output is compared to a group of eight series-connected saturated standard cells by means of a null detector.

\section{NBS}

Ten nominally equal $1000-\Omega$ resistors (resistor string) are driven by a $10.18-\mathrm{V}$ battery-operated solid-state source with good short-term stability. The voltage drop across each resistor is determined by comparing it to a standard cell, measuring the microvolt difference with a DVM. Then the sum of the output voltages developed across these resistors is compared to the output of the transport standard using the same DVM (see [1] for a detailed description).

\section{THE EXPERIMENT}

Three commercially available transport standards were used for the experiment. These standards were all of similar manufacture, containing an ovenized zener reference device at $48^{\circ} \mathrm{C}$, buffer amplifier, and resistive divider to provide outputs of $10,1.018$, and $1 \mathrm{~V}$, respectively. Measurements were made only on the $10-\mathrm{V}$ output. Two of the standards, serial numbers ( $\left.\mathrm{SN}^{\prime} \mathrm{s}\right) 10$ and 11 (owned by NBS), were shipped off-power and a third standard, SN 22 (supplied by the U.S. Army Primary Standards Laboratory (APSL)), was shipped under-power. One of the objectives of the experiment was to determine if shipping the standards off-power, which gives considerably more latitude in shipping schedules, would significantly degrade the transfer accuracy. Two types of measurements were made by each laboratory: a calibration of each of the transport standards with respect to the laboratory as-maintained $10-\mathrm{V}$ standard using the measurement scheme as described above; and a $3 \times 3$ intercomparison of the transport standards among themselves using a measurement design suggested in [2] and connection hardware supplied by NBS. (The intercomparison measurements were made to detect possible systematic errors in the laboratory measuring systems.) Data sheets, instructions sheets, shipping schedule, and addresses were sent along with the transpon standards. Each laboratory made ten measurements of the output of each of the three transport standards, and ten intercomparison design measurements of the transport standards. The transport standards were measured over a two week period at each laboratory and one additional week was allowed for shipping to the next laboratory and for settling. In this way, the desired measurements for the round-robin comparison could be carried out in an 18 week period. (Standard SN 22 was initially shipped to NBS from APSL and then all three standards were shipped together to each of the other laboratories $A-D$, in turn, and finally returned to NBS.)

\section{Experimental Results}

Two of the transport standards (SN's 10 and 11) were extensively tested at NBS prior to the experiment to determine the feasibility of shipping the units off-power. First the standards were tested in the laboratory by

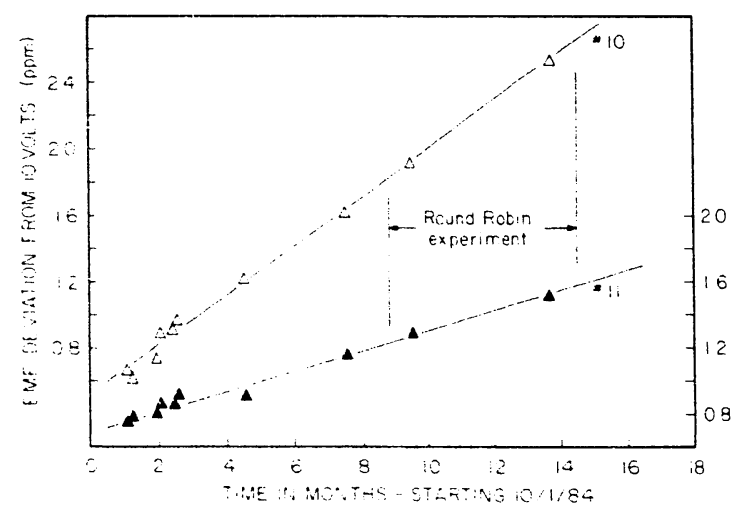

Fig. 1. Plot of voitages of standards, SN's 10 and 11 .

abruptly removing ac and battery power and allowing the ovens in the units to cool to room temperature for two days (typically Saturday and Sunday) to simulate shipping the units off-power. Power was restored Monday morning and one measurement was taken per day starting on Monday afternoon and continuing for the next five days. The weekly cycle was then repeated five times. The first six points for each of the standards in Fig. 1 represent the mean of the five (approximately) points taken each week between power interruptions. After the sixth week, actual shipments were begun. The standaru's were shipped from NBS, Gaithersburg, Maryland, by air freight to a California laboratory twice, and then shipped to the four DoD laboratories as part of the round-robin experiment previously described. The last four points of Fig. 1 are the calibrations of the two standards while at NBS. Each point represents the mean of from 11 to 64 daily measurements made at NBS between each shipment. Least-square lines were fitted to the data where each point was weighted inversely proportional to the number of daily measurements. The residual standard deviations based on an average of ten daily measurements are 0.047 and $0.060 \mathrm{ppm}$ for SN's 10 and 11 , respectively.

SN 22 was cycled on and off at APSL prior to shipment to NBS to determine if this cycling caused any shift in the output voltage. It was thought that there would be no significant change, but it was found that there was a considerable shift (about $0.4 \mathrm{ppm}$ ) in the output voltage. After ten calibration runs on this unit it was shipped underpower to NBS, joining the other two standards.

The round-robin experiment was started on July 19, 1985 and completed December 6, 1985. Five shipments between laboratories were planned, terminating at NBS by November 18, 1985; however, the planned schedule was slightly delayed due to some environmental difficulties and other minor problems in the measurement system at Lab D. The transport standards were shipped to each laboratory by overnight delivery service. SN 22 was kept warm during shipping by applying auxilliary battery power. The reference was accidently cooled to ambient temperature and power to the diode was interrupted on September 17, 1985 bccause the shipping package did not reach Lab C within the lifetime of the external battery ( 24 


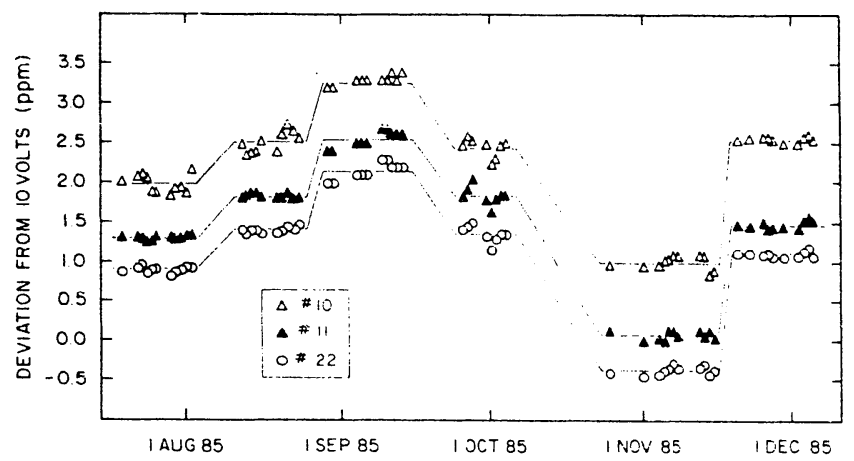

Fig. 2. Plots of voltages of the three standards as measured by each laboratory in terms of its $10-\mathrm{V}$ laboratory unit.

h). Although power cycling has previously caused a significant shift, in this case there was no observable change in the output voltage of SN 22. SN's 10 and 11 were presumably all right since they were shipped off-power; however, it was noted that these units experienced over $90 \mathrm{~g}$ of shock as indicated by the shock indicators mounted on them.

Fig. 2 shows the values of the three standards as determined at each laboratory in terms of their local laboratory volt. Each group of points represents data from NBS, Lab A, Lab B, Lab C, Lab D, and NBS, respectively. The horizontal line drawn through each group of data represents the mean value of that group. The angled lines are added only to guide the eye and do not necessarily indicate an actual shift in the voltages of the standards, but rather a difference in the laboratory units as maintained at $10 \mathrm{~V}$. The laboratory temperature and transport standard oven temperatures were recorded during the measurements; however, no corrections for temperature were applied to the data. Standards SN 10 and SN 11 were tested for sensitivity to temperature and found to have a temperature coefficient of $-0.004 \mathrm{ppm} /{ }^{\circ} \mathrm{C}$ with respect to ambient temperature.

At the conclusion of the experiment SN 22 was deliberately cooled at NBS by removing ac power and letting the batteries run down. After three days power was restored and measurements resumed. The difference of the mean of 17 measurements prior to the cooldown from the mean of six measurements after power was restored was $+0.02 \mathrm{ppm}$. The cause of the earlier shift at APSL could have been the sudden termination of battery and ac power rather than the gradual degradation of the battery voltage.

The values of the three standards were assumed to be linear in time and were estimated by a least-squares fit to the before and after NBS data [3]. Values for the standards while at Labs A-D were adjusted by subtracting the predicted values of the transfer standards from the values assigned by each of the laboratories. Table I gives the difference between the individual laboratory units of voltage and the NBS volt. The values in parenthesis are the deviation of the mean for each laboratory that was calculated from the data on each standard and represents the variance of measurement in the laboratory. The relative
TABLE I

$V_{\text {LAB }}-V_{\text {NBS }}$ (IN ppm) Determined Using Three 10-V Solid-State STANDARDS

\begin{tabular}{|c|c|c|c|c|c|c|}
\hline & & SN 22 & SN 10 & SN 11 & Mean & Std. Dev. \\
\hline LAB & A & $\left(\begin{array}{l}-0.46 \\
(0.011)\end{array}\right.$ & $\begin{array}{c}-0.42 \\
(0.042)\end{array}$ & $\begin{array}{c}-0.50 \\
(0.010)\end{array}$ & -0.46 & 0.040 \\
\hline LAB & B & $(0.034)$ & $(0.021)$ & $\begin{array}{c}-1.19 \\
(0.034)\end{array}$ & -1.15 & 0.038 \\
\hline LAB & c & $\begin{array}{l}-0.34 \\
(0.037)\end{array}$ & $\begin{array}{l}-0.16 \\
(0.042)\end{array}$ & $\begin{array}{l}-0.44 \\
(0.041)\end{array}$ & -3.32 & 0.142 \\
\hline$\angle A B$ & $D$ & $\begin{array}{c}+1.44 \\
(1.015)\end{array}$ & $\begin{array}{l}+1.47 \\
(0.027)\end{array}$ & $\begin{array}{c}+1.37 \\
(0.015)\end{array}$ & +1.42 & 0.047 \\
\hline
\end{tabular}

agreement among the units is good and the somewhat larger scatter at Lab C is possibly caused by severe shock encountered during shipment which damaged the power supply of standard SN 10.

The uncertainty in assigning a value to a solid-state standard while in a secondary laboratory based on calibrations performed by a primary laboratory can be estimated from the NBS data presented in Fig. 1. This uncertainty is quantified by the residual standard deviation of the least-squares fit and includes the uncertainty due to random NBS calibration error, shifts of the output voltage due to shipping, and random fluctuations in the output voltage. The rms total of the standard deviations of the two lines in Fig. 1 is 0.054 ppm with 16 degrees of freedom. The 95-percent confidence interval for the transfer uncertainty is thus estimated to be $0.11 \mathrm{ppm}$. This is the expected uncertainty with which a transfer could be carried out using a single transport standard. When the transport standard is used to assign a value to standards in a secondary laboratory an additional uncertainty must be in cluded for the random measurement error of the secondary laboratory. The data of Table 1 are consistent with this total uncertainty.

\section{CONCLUSION}

This experiment was satisfactory despite some shipping and other minor problems. The results clearly suggest the feasibility of establishing such a program with some modifications in technique. The estimated transfer uncertainty is comparable to the best obtainable using standard cells. Each of the laboratories participates in a Volt Transfer Program with NBS, thus we expect that $\mathrm{V}_{\mathrm{LAB}}-\mathrm{V}_{\mathrm{NBS}}$ at the $1-\mathrm{V}$ level is less than $0.4 \mathrm{ppm}$ (95-percent $\mathrm{CI}$ ). The Estimated uncertainty of $\mathrm{V}_{\mathrm{LAB}}-\mathrm{V}_{\mathrm{NBS}}$ using the solid-state standards is $0.27 \mathrm{ppm}$ (95-percent $\mathrm{CI}$ ) when the uncertainty of the NBS calibration in terms of the NBS volt is included. The difference $\mathrm{V}_{\mathrm{LAB}}-\mathrm{V}_{\mathrm{NBS}}$ for some laboratories was found to exceed the combined uncertainty, indicating possible measurement problems in scaling from 1-10 V. Since all the standards we used behaved similarly we conclude there was no observed degradation of the transfer uncertainty due to shipping two of them off-power. We caution the reader not to assume this is true for all solidstate standards; our sample of two does not prove this conclusively. 


\section{ACKNOWLEDGMENT}

The authors gratefully acknowledge the collaboration of individuals at the participating laboratories for their contributions to this experiment. They particularly thank R. Semer of the U.S. Air Force, W. Mikita and C. Kiser of the U.S. Navy Western and Eastern laboratories, and the Calibration Coordination Group of the U.S. Department of Defense.

\section{REFERENCES}

[1] B. F. Field, "A sub-PPM automated one-to-ten volt measuring system," IEEE Trans. Instrum. Meas., vol. IM-34, no. 2, pp. 327-330, June 1985.

[2] W. G. Eicke and J. M. Cameron, "Designs for surveillance $r$ the volt maintained by a small group of saturated standard cells," Nat. Bur. Stand., Tech. Note 430, 1967.

[3] N. R. Drager and H. Smith, Applied Regression Analysis, 2nd ed. New York: Wiley, 1981, pp. 1-69. 